\title{
КОНЦЕПТУАЛЬНАЯ МОДЕЛЬ ОЦЕНКИ ЭФФЕКТИВНОСТИ БИЗНЕС-ПРОЦЕССОВ ДЕРЕВООБРАБАТЫВАЮЩЕГО ПРЕДПРИЯТИЯ
}

\author{
(C) 2020 Чан Тхи Тхань Тхюи \\ Высшая инженерно-экономическая школа \\ Санкт-Петербургский политехнический университет Петра Великого (СПбПУ), \\ Россия, Санкт-Петербург \\ E-mail: thuytrannvcard@gmail.com
}

На современном этапе развития мировой экономики, в следствии неуклонно развивающегося процесса глобализации, мировые рынки промышленной продукции начинают испытывать состояние гиперконкуренции. Данное явление порождает необходимость поиска промышленными предприятиями принципиально новых и инновационных направлений повышения как эффективности использования ресурсов, так и повышения эффективности коммуникации. Однако, медиирование инновационного развития является оптимальной стратегией в первую очередь для высокотехнологичных отраслей промышленности, в то время как низкотехнологичные и среднетехнологичные отрасли обладают значительной зависимостью от традиционных технологий и ресурсной базы, что не позволяет им в полной мере ориентироваться на интеграцию и генерацию инновационных решений. Одной из наиболее выделяющихся в данной группе является деревообрабатывающая промышленность, значительно зависимая как от природно-ресурсной базы, так и от низкоквалифицированного человеческого труда. В связи с этим, особую значимость для деревообрабатывающих промышленных предприятий приобретает концептуальное управление операционной деятельностью в контексте стратегического развития. Центральным объектом управления при этом выступают бизнес-процессы, а целевым параметром - эффективность бизнес-процессов. В рамках данной статьи автор представляет разработанную концептуальную модель оценки эффективности бизнеспроцессов деревообрабатывающего предприятия.

Ключевые слова: бизнес-процессы, эффективность, деревообрабатывающая промышленность, экономический результат, нормирование затрат.

На основании анализа структуры деревообрабатывающей промышленности были выделены конкретные группы бизнес-процессов. Рассмотрим более детально каждую из выделенных групп.

1. Основные бизнес-процессы. Данные бизнес-процессы приносят основную прибыль предприятиям. Заметим, что деревообработка представляет собой сложный процесс превращения древесины в готовую продукцию, удовлетворяющую потребности потребителей. Организация основных бизнес-процессов на деревообрабатывающих предприятиях состоит в объединении людей, орудий и предметов труда в единый процесс производства продукции из древесины. Результатом указанных основных бизнес-процессов являются создание продукции из древесины по заказам потребителей, удовлетворяющей их потребностям.

2. Обеспечивающие бизнес-процессы. На предприятии деревообрабатывающей промыш- ленности указанные процессы представляют собой такие процессы, клиентами которых являются основные процессы, структурные подразделения, сотрудники предприятия и которые также поддерживают инфраструктуру предприятия. На предприятиях деревообрабатывающей промышленности результатом обеспечивающих бизнес-процессов является обеспечение ресурсами всех основных бизнес-процессов. К обеспечивающим процессам относят такие бизнеспроцессы, как закупка сырья и материалов, обеспечение качества продукции из древесины, подбор персонала, финансовое обеспечение, юридическое обеспечение, использование отходов производства, информационное обеспечение деятельности и т.д

3. Процессы управления. Эти процессы позволяют управлять предприятием, обеспечивая ее выживание, конкурентоспособность и развитие. Отличительной особенностью процессов управления является их типовая структура. 
4. Бизнес-процессы развития. Эта группа бизнес-процессов представляет собой инвестиционную и инновационную деятельность предприятий деревообрабатывающей промышленности. К ней можно отнести следующие бизнес-процессы: совершенствование выпускаемой продукции и бизнес-процессов, переобучение и развитие персонала, поиск возможностей использования новых материалов для производства, инновационные изменения в инфраструктуре, развитие технологий производства, использование инновационного оборудования для повышения качества выпускаемой продукции, обоснование инвестиционных проектов для развития бизнеса.

Приведенная обобщенная классификация бизнес-процессов предприятий деревообрабатывающей промышленности позволит сформировать эффективную систему управления предприятиями и тем самым достичь поставленных целей и задач субъектами хозяйствования с наименьшими затратами. Это позволит также повысить уровень конкурентоспособности, достичь удовлетворения потребностей потребителей.

Современный подход к созданию системы управления бизнес-процессами организации основан на современном понимании процессного подхода к управлению. Бизнес-процесс, методологически, является достаточно сложным объектом управления. Система управления процессами организации, включающая действия по преобразованию входных данных в выходные, системы сбора информации о показателях процесса, системы анализа этой информации и принятия решений. управление лицом, ответственным за эффективность процесса, система постоянно совершенствует показатели процесса и корректирующие действия по устранению причин отклонений процесса. Метод создания системы управления процессами должен основываться на принципах системы менеджмента качества, определенных в соответствии с международными стандартами ISO 9000:2000. Сочетание принципов организационного управления и методов управления качеством позволяет организации любого уровня сложности построить эффективную систему управления каждым процессом, связать отдельные процессы в единый системный и интегрированный процесс. В эту систему управления входит механизм постоянного совершенствования деятельности орга- низации.

Одним из целевых параметров управления бизнес-процессами является их эффективность. Сущностно, параметр эффективности бизнеспроцесса неизменно определяется как отношение полезного результата к затратам на его достижение. Следовательно, каждый бизнеспроцесс можно охарактеризовать двумя базовыми параметрами:

1. Количественное выражение полезного результата. Данный параметр характеризует объем сгенерированного в рамках бизнеспроцесса блага, измеряемого как в натуральном выражении, так и конвертируемого в денежное выражение.

2. Количественное выражение затрат на достижение полезного результата. Данный параметр характеризует объем затраченных на реализацию бизнес-процесса ресурсов.

Отношение количества полезного результата к затратам на достижение полезного результата в рамках бизнес-процесса определяет его эффективность. Однако, полный цикл производства в рамках деревообрабатывающей промышленности, достаточно растянутый во времени, и не позволяет моментно определять фактическую эффективность бизнес-процесса, так как полезный результат растянут во времени. При этом операционная или моментная эффективность в рамках деревообрабатывающего промышленного предприятия является крайне значимой, так как:

1. Моментная эффективность бизнеспроцесса позволяет принимать операционные решения в рамках оптимизации плана производства, что значительно повышает эластичность функционирования предприятия;

2. Понимание моментной эффективности бизнес-процессов позволяет корректировать плановую эффективность производства в целом.

Таким образом, процесс оценки эффективности бизнес-процессов необходимо дифференцировать. В случае деревообрабатывающей промышленности, можно утверждать, что принципиальная дифференциация может быть ограничена двумя последовательными элементами:

1. Оценка моментной эффективности бизнес-процессов (ВРЕ). В данном случае производится последовательная оценка эффективности каждого бизнес-процесса и определение чувствительности последующих бизнес-процессов к возможным фактическим отклонениям. Мо- 
ментная эффективность бизнес-процессов может быть представлена в виде отношения фактических затрат на реализацию бизнес-процесса (C) к их нормативному или планируемому значению (Е). Данная оценка дифференцируется не только в пространстве, но и во времени, что в свою очередь определяет необходимость учета влияния фактических отклонений данных показателей от нормативных или планируемых на значения показателей последующих бизнеспроцессов.

2. Оценка результирующей эффективности бизнес-процессов (RBPE). Данный показатель определяется отношением фактического результата деятельности предприятия (R.R.), в качестве которого может выступать как объем реализации в денежном выражении, так и различные уровни прибыли, к фактическим затратам на достижение данного результата, также выраженным в денежном выражении (R.C.). Данный показатель также может обладать планируемым значением.

Таким образом данная дифференциация позволит выразить полный производственный цикл совокупность относительных значений, связей между ними и чувствительностью к трансформации. На рисунке 1 представлена концептуальная модель трансформации результирующей эффективности бизнес-процессов деревообрабатывающего предприятия. Как можно видеть на приведенном рисунке, каждый из возможных бизнес-процессов может оказывать влияние не последующие бизнес-процессы, и, как следствие, на показатель результирующей эффективности бизнес-процессов.

В соответствии с вышесказанным, процесс оценки эффективности бизнес-процессов деревообрабатывающего предприятия может быть представлен следующим последовательными инструментами:

1. Инструмент определения нормативных затрат реализации бизнес-процесса (Е).

2. Инструмент определения фактических затрат реализации бизнес-процесса (C).

3. Инструмент определения фактического результата деятельности предприятия (R.R.).

4. Инструмент определения фактических затрат по достижению результата деятельности предприятия (R.C.).

B данном случае, калькуляция фактических затрат реализации бизнес-процесса (C) может производиться на основе фактических данных, источниками которых выступают документы управленческого и бухгалтерского учета. Фактические затраты по достижению результата деятельности предприятия (R.C.) калькулируются аддитивно, как сумма фактических затрат реализации всем бизнес-процессов. Фактический результат деятельности предприятия (R.R.) также определяется на основе бухгалтерской и управленческой документации. Наиболее специфичным и комплексными для целей калькуля-

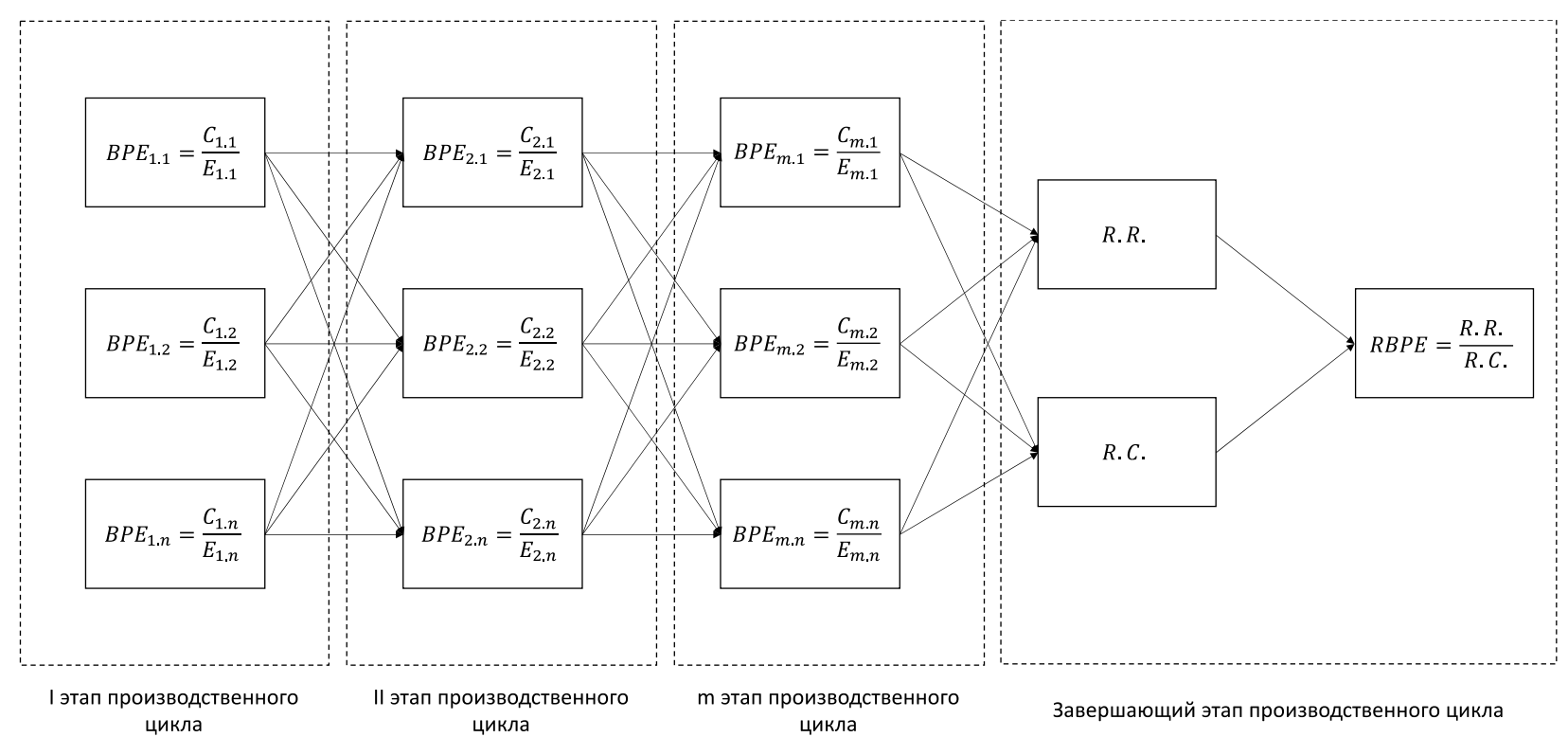

Рисунок 1. Концептуальная модель трансформации результирующей эффективности бизнес-процессов деревообрабатывающего предприятия 
ции являются нормативные затраты реализации бизнес-процесса (Е). В рамках данного параграфа будет рассмотрен данный инструмент с методической точки зрения. Необходимо отметить, что в качестве примера будет рассмотрена методика определения нормативных затрат реализации бизнес-процессов цеха по производству изделий из деревянного шпона с применением технологии лазерной резки. Данная методика является не универсальной, и разработана для применения в рамках конкретного предприятия, при использовании конкретной технологии. Однако, сами принципы и этапы разработки методики являются универсализированными, и могут быть применены для описания фактически любого бизнес-процесса в рамках деревообрабатывающего промышленного предприятия.

Ключевыми информационными источниками для калькуляции нормативных затрат выступают входная информация о заказе, ин- формация о ресурсной специфике предприятия и статистическая информация производственного характера. В соответствии с данной совокупностью информации, могут быть сформулированы следующие этапы методики калькулирования нормативных затрат реализации бизнес-процесса:

1. Формирование модели полного цикла выполнения заказа на предприятии.

2. Детализация структуры затрат реализации бизнес-процессов каждого этапа цикла по элементам.

3. Выявление способов определения каждого элемента затрат реализации бизнеспроцессов,

4. Формирование консолидированной аддитивной модели.

5. Разработка системы уточняющих показателей, и их интеграция в консолидированную модель.

\section{Библиографический список}

1. Барсков В.В., Белостоцкая А.А., Забелин Б.Ф., Конников Е.А. Актуальные вопросы производственного менеджмента в практической деятельности промышленного предприятия // Монография. Казань, 2017.

2. Вайцеховская, С.С., Дыкань, Ю.А., Петренко, А. О. Особенности бизнес-процессас позиции процессного подхода к управлению. Сборник научных трудов Sworld. 2013. Т. 30. № 1. С. 52-56

3. Госстандарт. ГОСТ Р ИСО 9001-2008. Системы менеджмента качества. Требования - М.: Стандартинформ, 2008. -65 c.

4. Жогова E.В., Зайцев А.А., Родионов Д. Г. Инструментальные методы оценки региональной промышленной политики // Российский экономический интернет-журнал. 2019. № 2. С. 35.

5. Заборовская О.В., Жогова Е.В. Инструментарий обеспечения инвестиционных процессов реализации региональной промышленной политики // Российский экономический интернет-журнал. 2018. № 4. С. 40.

6. Зиндер Е.3. Новое системное проектирование: информационные технологии и бизнес-реинжиниринг// Системы управления базами данных. - 1996. - № 1.- 55-67

7. Клочков Ю.С., Конников Е.А. Трансформация структуры производственной себестоимости на промышленном предприятии в процессе интеграции аддитивных технологий // Известия Самарского научного центра Российской академии наук. 2019. Т. 21. № 1 (87). С. 5-10.

8. Конников Е.А., Барсков В.В. Цель российской промышленности и результаты ее достижения на современном этапе // Экономика и предпринимательство. 2015. № 11-2 (64). С. 167-170

9. Конников Е.А., Белостоцкая А. А., Забелин Б. Ф. Показатели обеспеченности ресурсами как критерии оценки финансового состояния промышленного предприятия // Экономика и предпринимательство. 2015. № 12-1 (65). С. 771-776.

10. Короткевич М.З., Повышение качества бизнес - процессов предприятия на основе операционного управления их изменениями. Автореферат диссертации на соискание ученой степени кандидата экономических наук. Москва., 2013., С. 25.

11. Минаева Е. В. Система направлений повышения эффективности управления бизнес-процессами // Наука и Мир. 2014. Т. 2. № 5 (9). С. 36-38.

12. Родионов Д.Г., Кудрявцева Т. Ю. Механизм и принципы формирования кластерной промышленной политики // Инновации. 2018. № 10 (240). С. 81-87

13. Фидельман Г.И. Бизнес-процессы и изменение организации // Методы Менеджмента качества.- 2002.№ $1 .-$ С. $14-18$ 